\title{
COLLOID CYST OF BRAIN
}

\author{
Aashfa Hassan
}

\begin{abstract}
Colloid cysts are benign congenital cysts that arise in the anterior part of the third ventricle of brain at the level of foramen of Monro and constitute $1 \%$ of all cerebral tumors. They occur usually in the younger age and are asymptomatic unless they compress foramen of Monro and cause hydrocephalus. They can be symptomatic and fatal, if not treated properly. A case is reported here who had an outside referral for CT Scan of brain with main complaints of persistent recurrent headache and positional vertigo.
\end{abstract}

KEY WORDS: Colloid cyst. Headache. Vertigo. Hydrocephalus.

\section{INTRODUCTION}

Colloid cyst comprises of $1 \%$ of CNS tumors as reported in the West. The origin of colloid cysts has long been debated. Possibly, they are derived from paraphysis and have been termed paraphyseal cysts. The other theory is that cells of its origin include neuroepithelial ependymal lining, choroid and telachoridea. ${ }^{1}$ It consists of round encapsulated structure containing a grayish translucent material. They may be asymptomatic and found incidentally on CT Scan/ MRI when patients are imaged for other reasons. Younger patients have increased frequency of presenting with chronic recurrent headache, blurring vision, vomiting and vertigo, which may be intermittent and positional, because of transient CSF obstruction. With severe obstruction, they may present with headache, nausea, vomiting, ataxia, visual disturbances, depolarization and increased sleepiness. ${ }^{2}$ Typical positioning of round or oval lesion in the anterior superior portion of third ventricle of the foramen of Monro with non-enhancing area of high attenuation is almost diagnostic. ${ }^{3} \mathrm{MRI}$ is preferred by some, although CT has been suggested sufficient for the diagnosis. ${ }^{4}$ Intraventricular hemorrhage occasionally mimics a colloid cyst on CT and MRI . Migratory neurocysticercosis, central neurocytomas and subepindymal astrocutomas may occur in the same area and come in the differential diagnosis of colloid cysts, but they can be distinguished by their shape, contrast enhancement and signal activity. ${ }^{5}$

\section{CASE HISTORY}

A young boy of 16 years age was referred by a local doctor working outside this hospital with the complaints of chronic intermittent headache not relieved by analgesics, vertigo, nausea, vomiting and blurring of vision for the last 7-8 years with suspected diagnosis of tumor/ vascular malformation. On examination, his B.P. was $120 / 80 \mathrm{mmHg}$, pulse 90 beats/ minute (regular) and carotids and peripheral pulses were also normal. Cardiovascular system, higher mental functions including all cranial nerves were also normal. He had fine tremors, and vertigo on closure of both eyes. Motor and sensory systems were normal. Fundoscopy was also normal, with no signs of raised intracranial pressure. CT scan showed an oval mass of about $2.5 \mathrm{~cm}$ in the anterior of third ventricle with non-enhancing areas of high attenuation. However, there was no central enhancement. The lateral ventricles were mildly dilated (Figure I). Diagnosis of colloid cyst was made because of shape, position and above findings on scan. The case was referred to Neurosurgical department, where the lesion was removed and the diagnosis confirmed as colloid cyst.

\section{FIGURE I:}

\section{ROUND MASS IN THE ANTERIOR PART OF THIRD VENTRICLE AND MILD DILATATION OF LATERAL VENTRICLES}

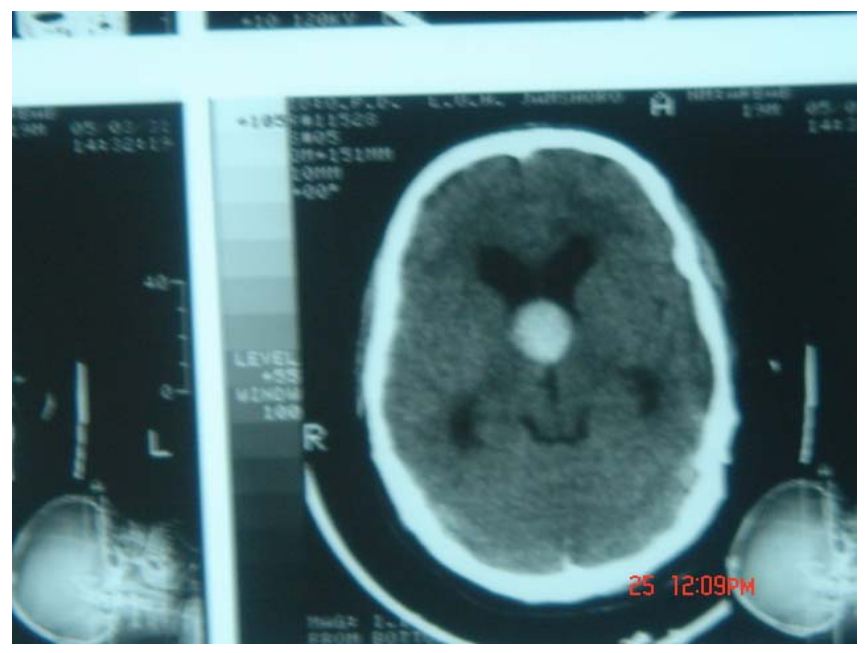




\section{DISCUSSION}

Colloid cyst of third ventricle is a rare manifestation. Headaches and vertigo could be the manifestation of several diseases and often ignored by patients as well as physicians. Even in the West, colloid cyst is often an incidental finding unless the patient develops hydrocephalus. Awareness of this treatable disease might prevent complications and sudden death. Colloid cysts are benign congenital epithelium lined cysts containing amorphous gelatinous material that lies in the roof of third ventricle directly behind the foramen of Monro. Because of its position, it can give rise to intermittent obstruction of foramen of Monro. They are usually $1-2 \mathrm{~cm}$ in diameter but can be larger. ${ }^{6}$ It usually occurs in younger age groups, but have been reported in the 5-6th decades of life as well. It may be familial but no chromosomal abnormalities have been found so far. It is supposed to be a vestigial structure of paraphysis. ${ }^{7}$ In one study $^{8}, 58$ symptomatic patients were followed for a mean period of 79 months. The results showed no incidence of symptoms upto 5 years and $8 \%$ incidence of symptoms upto 10 years suggesting that the lesion can be monitored safely. The appearance of the cyst on CT and MRI is important in planning treatment, as the success rate after percutaneous aspiration is lower in those with high attenuation on CT and decreased T2 signal intensity in those with fluid characteristics. Interestingly, cysts with higher T2 signals intensity are easier to treat with minimal invasive surgical techniques and are also most likely to cause clinical symptoms., ${ }^{9,10}$ Colloid cysts do not have intrinsic enhancement and its presence suggests a solid tumor. However, peripheral enhancement suggests vascularity in the outer wall.

\section{CONCLUSION}

The diagnosis of colloid cyst is made, based on the classic location, appearance and signal activity. Central contrast enhancement suggests an alternative diagnosis, but most other pathologies occurring in this location are easily distinguishable from colloid cysts.

\section{REFERENCES}

1. Cotron RS, Kumar V, Robinson SL. Pathological Basis of Disease. $5^{\text {th }}$ Ed. Philadelphia, W.B. Saunders. 1994; p.1346.

2. Shemie S, VvRutka J, Armstrong D. Acute obstructive hydrocephalus and sudden death in children. Ann Emerg Med. 1997; 29(4): 524-8.

3. Mamourian AC, Cromwell LD, Harbaugh RE. Colloid cyst of third ventricle; sometimes more conspious on CT than MRI. AJNR Am J Neuroradiol. 1998; 19(5):875-8.

4. Scotti G, Scialfa G, Colombo N, Landoni L. MRI in the diagnosis of colloid cysts of the third ventricle. AJNR Am J Neuroradiol. 1987;8 (2): 370-2.

5. Wray SD, Ellis TL, Bianco S. Migratory neurocysticercosis mimicking a third ventricular colloid cyst: a case report. J Neurosurg. 2001; 95 (1):122-3.

6. Sutton D. Text book of Radiology and Imaging. Vol 2, 6th Ed, 1998; p. 1601.

7. Stoodley MA, Nguyen TP, Robinson P. Familial fatal and near fatal third ventricle colloid cysts. Aust J Surg. 1999;69(10):733-6.

8. Mathiesen T, Grane P. Third ventricle colloid cysts; a consecutive 12 years series. J Neurosurg. 1997; 86(1):5-12.

9. Abdou MS, Cohen AR. Endoscopic treatment of colloid cysts of third ventricle. Technical note and review of the literature. J Neurosurg. 1998; 89 (6):1062-8.

10. EL Khoury C, Brugieres P, Decg P, CossonStanescu R, Combes C, Ricolfi F, et al. Colloid cysts of third ventricle: are MR imaging patterns predictive of difficulty with percutanous treatment? AJNR Am J Neuroradiol 2000; 21 (3):489-92.
AUTHOR AFFILIATION:
Dr. Aashfa Hassan
Medical Officer
Department of Radiology and Imaging
Liaquat University Hospital, Hyderabad - Sindh. 